\title{
Estimation of Snowfall Properties at a Mountainous Site in Norway Using Combined Radar and In Situ Microphysical Observations
}

\author{
Claire E. Schirle And Steven J. CoOPer \\ University of Utah, Salt Lake City, Utah \\ MAREILE ASTRID WOLFF \\ Norwegian Meteorological Institute, Oslo, Norway \\ Claire Pettersen, Norman B. Wood, And Tristan S. L'Ecuyer \\ University of Wisconsin-Madison, Madison, Wisconsin \\ TROND ILMO AND KNUT NYGÅRD \\ Norwegian Meteorological Institute, Oslo, Norway
}

(Manuscript received 19 October 2018, in final form 13 March 2019)

\begin{abstract}
The ability of in situ snowflake microphysical observations to constrain estimates of surface snowfall accumulations derived from coincident, ground-based radar observations is explored. As part of the HighLatitude Measurement of Snowfall (HiLaMS) field campaign, a Micro Rain Radar (MRR), Precipitation Imaging Package (PIP), and Multi-Angle Snow Camera (MASC) were deployed to the Haukeliseter Test Site run by the Norwegian Meteorological Institute during winter 2016/17. This measurement site lies near an elevation of $1000 \mathrm{~m}$ in the mountains of southern Norway and houses a double-fence automated reference (DFAR) snow gauge and a comprehensive set of meteorological observations. MASC and PIP observations provided estimates of particle size distribution (PSD), fall speed, and habit. These properties were used as input for a snowfall retrieval algorithm using coincident MRR reflectivity measurements. Retrieved surface snowfall accumulations were evaluated against DFAR observations to quantify retrieval performance as a function of meteorological conditions for the Haukeliseter site. These analyses found differences of less than $10 \%$ between DFAR- and MRR-retrieved estimates over the field season when using either PIP or MASC observations for low wind "upslope" events. Larger biases of at least 50\% were found for high wind "pulsed" events likely because of sampling limitations in the in situ observations used to constrain the retrieval. However, assumptions of MRR Doppler velocity for mean particle fall speed and a temperature-based PSD parameterization reduced this difference to $+16 \%$ for the pulsed events. Although promising, these results ultimately depend upon selection of a snowflake particle model that is well matched to scene environmental conditions.
\end{abstract}

\section{Introduction}

Northern Hemisphere, high-latitude regions are undergoing some of the largest transformations attributed to climate change, in a process known as Arctic amplification (Chapman and Walsh 1993; Manabe and Stouffer 1980; Nicholls et al. 1996; Holland and Bitz 2003; Serreze and Francis 2006; Bekryaev et al. 2010).

Corresponding author: Steven J. Cooper, steve.cooper@ utah.edu
Because of warming trends, alterations in the spatial distribution of snowfall and ice cover in high-latitude regions (Brown 2000; Holland et al. 2006; Bindoff et al. 2013) feed back on the climate system through impacts on albedo and surface energy budgets (Cohen and Rind 1991; Vavrus 2007; Screen and Simmonds 2010; Crook et al. 2011). Snowfall also acts to build and maintain the Greenland and Antarctic ice sheets (Lenaerts et al. 2013; Palerme et al. 2014, 2017; Pettersen et al. 2018). Melting from these ice sheets contributes to rising sea levels around the globe, which may have detrimental 
impacts on low-lying, coastal communities (Shepherd and Wingham 2007; Gardner et al. 2013; Jacob et al. 2012; Van Tricht et al. 2016). Given these sensitivities and outcomes, it is essential to understand snowfall processes and to accurately quantify snowfall in these remote, high-latitude regions where ground observations are sparse.

The launch of the CloudSat 94-GHz Cloud Profiling Radar (CPR) in 2006 provided the first opportunity to examine the vertical structure of snowfall at a global scale (Stephens et al. 2018). Several studies, such as Matrosov et al. (2008) and Liu (2008), have shown that the CPR can be used to estimate snowfall rate but that these values depend heavily upon assumed snowflake microphysical properties (Kulie and Bennartz (2009). The use of traditional $Z_{e}-S$ relationships, in which snowfall rate is derived only from knowledge of radar reflectivity, therefore can lead to large retrieval errors for a given snowstorm.

Other approaches have incorporated explicitly scenedependent microphysical information into the retrieval scheme to reduce this nonuniqueness. The operational CloudSat snowfall retrieval scheme [CloudSat 2C-Snow Water Content and Snowfall Rate (2C-SNOW-PROFILE); Wood and L'Ecuyer 2018] employs an a priori particle size distribution (PSD)-temperature relationship (Wood 2011). Use of the flexible optimal-estimation framework (Rodgers 2000) allowed the combination of PSD-temperature parameterizations with CPR reflectivities to derive a best estimate of snowfall properties consistent with both. Snow particle models (Wood et al. 2015) with associated reflectivity and mass-particle dimension relationships were designed for this CloudSat scheme based on observations from the Canadian CloudSat-CALIPSO Validation Project (C3VP) (Hudak et al. 2006) and discrete dipole approximation (DDA; Draine and Flatau 1994) simulations of scattering properties.

Even with such constraints, however, the CloudSat scheme can still lead to uncertainties in the instantaneous retrieved snowfall rates of up to $100 \%-200 \%$ (Wood 2011). These large uncertainties arise, in part, from the great variance in snow microphysical properties observed in nature (e.g., Mitchell 1996, and references therein; Passarelli 1978) and in associated radar scattering properties. In response, Cooper et al. (2017, hereafter C17), explored the use of in situ, event-specific observations of snow microphysical properties to constrain radar-based retrievals of snowfall. This work was based on observations from the Ka-band ARM Zenith Radar (KAZR) and Multi-Angle Snowflake Camera (MASC) deployed at the Atmospheric Radiation Measurement (ARM) North Slope Alaska (NSA) Climate Facility at Barrow, Alaska (now known as Utqiagivik), in spring 2014. This retrieval scheme for $35-\mathrm{GHz}$ groundbased radar used optimal estimation and elements from the CloudSat snowfall retrieval. But instead of using a temperature-dependent parameterization of PSD, C17 introduced the in situ observations of PSD through the a priori terms of the optimal-estimation framework.

Preliminary analyses suggested good performance for this retrieval scheme at Barrow. Estimates of snowfall from this approach differed by $18 \%$ relative to nearby National Weather Service snow gauge measurements of total accumulation over multiple snow events. Given the limited snowfall observed during the short MASC deployment at Barrow, however, it was not possible to come to definitive conclusions about the veracity of the technique nor understand how it might perform under varying meteorological conditions.

We expand upon the Barrow study by considering results from the National Science Foundation (NSF)sponsored High-Latitude Measurement of Snowfall (HiLaMS) field campaign that took place in Haukeliseter, Norway, in winter 2016/17, and Kiruna, Sweden, in winter 2017/18. This project deployed a Micro Rain Radar (MRR), Precipitation Imaging Package (PIP), and MASC in an attempt to understand snowfall microphysics and processes as a function of environmental conditions. In this paper, we explore the use of MASC and PIP snowflake microphysical observations to constrain a snowfall retrieval algorithm based upon the 24-GHz MRR. The Norwegian Meteorological Institute (Met Norway) Test Site at Haukeliseter experienced a variety of snowfall conditions and provided independent calibrated instrumentation for evaluating these retrievals.

Section 2 describes the Haukeliseter Test Site, HiLaMS instrumentation, and the optimal-estimation snowfall retrieval algorithm. Section 3 discusses observed snow particle habits, size distributions, and fall speeds as a function of two distinct and dominant storm regimes observed at Haukeliseter. Section 4 presents sample snowfall retrieval cases for each of these storm regimes to illustrate retrieval technique and sensitivities. Section 5 quantifies retrieval performance for total snowfall accumulation over the duration of the field campaign. Section 6 discusses the overall conclusions from the Haukeliseter Test Site efforts as well as future work.

\section{Data and methods}

\section{a. Haukeliseter test site and instrumentation}

The Norwegian component of the HiLaMS field campaign took place from October 2016 to April 2017 in the mountainous Telemark region of southern Norway at the Haukeliseter Test Site research station run by Met Norway, as shown in Fig. 1. This site is located on a 

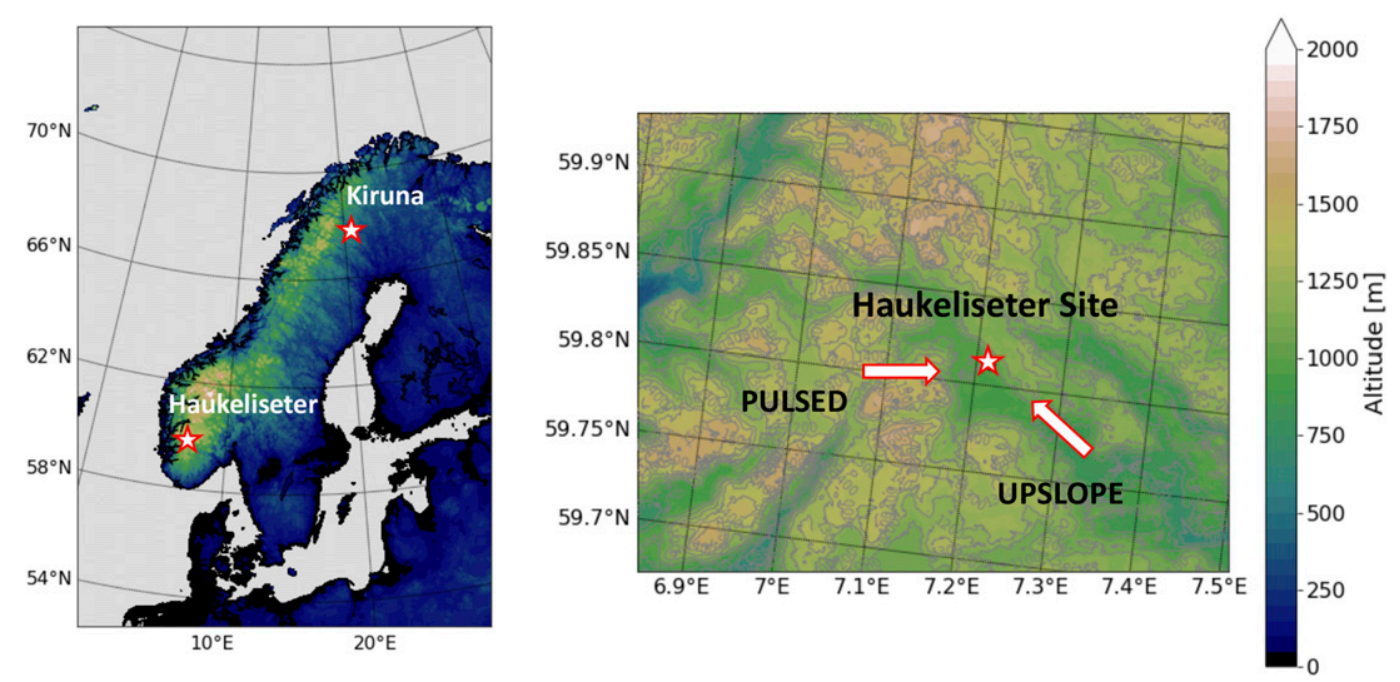

FIG. 1. (left) The location of Haukeliseter Test Site in the mountains of the Telemark region of Norway as well as the Kiruna site in the Swedish arctic. (right) Topographical map for the Haukeliseter region. The arrows denote $10-\mathrm{m}$ wind direction for the two predominate snow event regimes observed during HiLaMS.

plateau at $59.8^{\circ} \mathrm{N}$ and at an elevation of $991 \mathrm{~m}$ above sea level. The average annual precipitation at Haukeliseter is close to $800 \mathrm{~mm}$ (liquid equivalent), of which half falls as frozen precipitation between the months of October and April (Wolff et al. 2015). These precipitation totals are partly attributed to the atmospheric rivers from the North Atlantic that strike Norway (Waliser and Guan 2017), and are further enhanced by the steep orography of southern Norway (Stohl et al. 2008; Steensen et al. 2011). Additionally, the Scandinavian Peninsula is near the end of the midlatitude storm track that runs across the North Atlantic (Wernli and Schwierz 2006) providing numerous storm events for the site during a typical winter.

The Haukeliseter Test Site houses multiple precipitation gauges, thermometers, anemometers, and other basic meteorological observations needed for our snowfall analyses.

Geonor T-200B3 precipitation gauges located either inside a double fence intercomparison reference (DFIR; Goodison et al. 1998), denoted as a double fence automated reference (DFAR; Kochendorfer et al. 2018), or inside a single Alter wind shield provide measurements of liquid water equivalent (LWE) of snow accumulation at 1-min temporal resolution. The DFAR is considered "truth" for our analyses given that it provides a more accurate estimate of accumulation than the single gauge, especially in windy conditions such as those found at Haukeliseter (Rasmussen et al. 2012; Wolff et al. 2015, Kochendorfer et al. 2018). Figure 2 shows the snow gauges at the site. Mast-mounted anemometers at a height of $10 \mathrm{~m}$ provided wind direction and speed measurements.
The accurate measurement of snowfall amount from precipitation gauges is challenging (Goodison et al. 1998; Rasmussen et al. 2012). Numerous studies over the past century have sought to quantify uncertainties in these measurements and then provide a correction factor for environmental conditions (e.g., Black 1954; Larson and Peck 1974; Yang et al. 1998, 2005). During windy and turbulent conditions, for example, the gauges will likely underestimate snowfall amount as the snowflakes may not settle into the gauge opening. Overall, collection efficiency is a complex function of instrument design, shielding, wind, turbulence, temperature, and topography among other factors (Folland 1988; Goodison et al. 1998; Rasmussen et al. 2012; Thériault et al. 2015). Long-term evaluations of another DFIR against a bush gauge suggests that the DFIR experiences mean undercatch of about $10 \%$ under moderate windy conditions (i.e., less than $10 \mathrm{~m} \mathrm{~s}^{-1}$; Yang 2014).

\section{b. HiLaMS instrumentation}

The MRR, PIP, and MASC were deployed on the roof of a site building, as shown in Fig. 2. This location was selected to mitigate the effects of blowing snow and limit intrusions from seasonal snow accumulation and drifting. Given safety and logistical issues at the site, neither the MASC nor PIP were shielded from ambient winds.

The MRR is a frequency-modulated, continuouswave, vertically pointing radar that operates at a frequency of $24 \mathrm{GHz}$ (Klugmann et al. 1996). It provides observations of effective reflectivity, Doppler velocity, and spectral width. A noise removal technique (Maahn and Kollias 2012) was applied to the MRR observations 


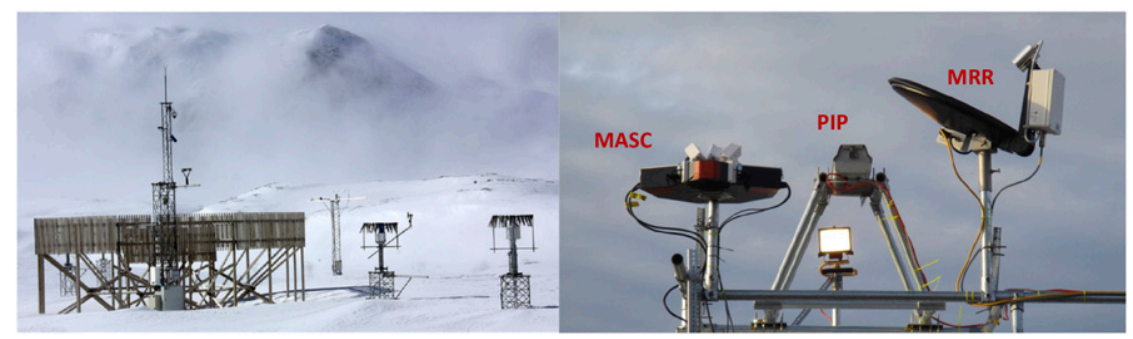

FIG. 2. (left) Double-fenced and single-shielded precipitation gauges at the Haukeliseter Test Site. (right) Multi-Angle Snowflake Camera (MASC), Precipitation Imaging Package (PIP), and Micro Rain Radar (MRR) as deployed atop the site command container.

to increase radar sensitivity down to an effective reflectivity as low as $-10 \mathrm{~dB} Z_{e}$. Such a value is sufficient for detection of measurable snowfall accumulation amounts for typical snow PSD conditions observed at Haukeliseter. MRR profile data are available for range gates at heights of 300 to $3000 \mathrm{~m}$ above ground level (AGL) with a vertical resolution of $100 \mathrm{~m}$ and temporal resolution of $1 \mathrm{~min}$.

The MASC captures high-resolution images of falling snow from which estimates of snowflake microphysical properties can be derived. The MASC contains three cameras pointed toward a common focal point in the center of the instrument sampling ring. As snowflakes fall through this sampling ring, they activate two nearinfrared sensors that trigger the cameras and illumination flashes. The sampling area through which the snowflakes must fall to trigger the sensors is $\sim 31 \mathrm{~cm}^{2}$ (Garrett et al. 2012). From the high-resolution images produced by the MASC, maximum dimension, shape, and complexity can be found for each falling snowflake (Garrett et al. 2012, 2015). Complexity is a measure of the sphericity of a particle and can be used to differentiate between types of particles such as rimed or pristine crystals. The fall speed of the snowflake is determined by measuring the time it takes to fall between the vertically aligned infrared sensors.

The PIP is a video imager that captures images ( 380 frames per second) of falling hydrometeors from which snow PSDs and fall speeds are derived. It is composed of a high-speed video camera located $\sim 2 \mathrm{~m}$ away from a halogen lamp which illuminates falling precipitation. The PIP sampling area is a $64 \mathrm{~mm}$ by $48 \mathrm{~mm}$ FOV at a focal point of $\sim 1.33 \mathrm{~m}$ within the unobstructed $2 \mathrm{~m}$ by $0.5 \mathrm{~m}$ distance between the video camera and lamp (Newman et al. 2009; Tiira et al. 2016). The PIP design with its open sampling volume reduces the creation of turbulence from the apparatus itself, giving particle motions and velocities that are likely an accurate representation of conditions present during a snow event (Newman et al. 2009).

\section{c. MRR snowfall retrieval algorithm}

The optimal-estimation snowfall retrieval scheme developed for the 35-GHz KAZR at Barrow and used in C17 was modified to the $24-\mathrm{GHz}$ frequency used by the MRR. To understand how we incorporate observations of snow microphysical properties into the retrieval scheme, it is helpful to first review the structure of the optimal-estimation approach. Optimal estimation essentially reduces to minimizing a scalar cost function to obtain the state vector $\mathbf{x}$ (Rodgers 2000), as in Eq. (1):

$$
\begin{aligned}
\Phi(\mathbf{x}, \mathbf{y}, \mathbf{a})= & {[\mathbf{y}-F(\mathbf{x})]^{\mathrm{T}} \mathbf{S}_{\mathbf{y}}^{-1}[\mathbf{y}-F(\mathbf{x})] } \\
& +(\mathbf{x}-\mathbf{a})^{\mathrm{T}} \mathbf{S}_{\mathbf{a}}^{-1}(\mathbf{x}-\mathbf{a})
\end{aligned}
$$

For our study, the vector $\mathbf{x}$ represents the snow PSD and contains the slope parameter $(\lambda)$ and number intercept $\left(N_{0}\right)$ for an assumed exponential size distribution for each radar range bin, as in Eq. (2), where $D$ is particle dimension:

$$
N(D)=N_{0} e^{-\lambda D} .
$$

The best estimate of vector $\mathbf{x}$ depends on both the observation vector $\mathbf{y}$ and the a priori state vector $\mathbf{a}$. The observation vector contains MRR reflectivity profiles, while the a priori vector defines the a priori estimates for the PSD parameters. $\mathbf{S}_{\mathbf{y}}$ defines the uncertainties in both the MRR measured reflectivities and the forward model assumptions used to calculate simulated reflectivities from given PSD parameters and an assumed particle model. We used an $\mathbf{S}_{\mathbf{y}}$ standard deviation value of $2.5 \mathrm{~dB} Z_{e}$ for the diagonal matrix elements for this study based upon variation in simulated reflectivities arising from the use of different particle model assumptions. This value is similar to that found from $\mathrm{C} 17$ and Hammonds et al. (2014) for $35-\mathrm{GHz}$ calculations. $\mathbf{S}_{\mathbf{a}}$ is the uncertainty in the PSD a priori estimates. The model-measurement differences and the differences between the a priori and retrieved state are weighted using the corresponding covariance matrix. 
Once the vector $\mathbf{x}$ is found through Newtonian iteration, the best estimate of PSD coefficients can be used with assumed particle model mass-particle dimension relationships to calculate the snow water content (SWC). The SWC, in turn, can be transformed into a precipitation rate using fall speed observations from the MASC, PIP, or MRR. To obtain the surface snowfall rate, an estimate of fall speed is applied to multiply the SWC in the clutterfree MRR radar bin nearest the surface. For the MASC and PIP, these fall speed estimates are population means of the particles observed by the instrument. For the leveled MRR, the fall speed estimates are the Doppler velocities in the SWC-containing radar bin as derived from the technique described in Maahn and Kollias (2012). That approach found good agreement between MRR Doppler velocities and those from a calibrated pulse Doppler radar.

As in $\mathrm{C} 17$, observations of snow microphysical properties from the MASC and PIP are introduced into the retrieval algorithm through the a priori terms and fall speed metric. MASC images were processed to quantify maximum particle dimension for each snowflake according to the techniques developed in Garrett et al. (2012), Garrett and Yuter (2014), and Garrett et al. (2015). An exponential size distribution function was fitted to particle size histograms from the MASC and from observed PSDs from the PIP to obtain the slope parameter $(\lambda)$. These fits were performed for particles larger than $0.7 \mathrm{~mm}$. We derived estimates of $\lambda$ either for entire snow events or for subsections of the events based upon differences in storm morphology, for example, areas of similar observed MRR reflectivity. It was necessary to build particle size histograms in such a manner over time given the relatively infrequent measurements from the MASC during light or moderate snowfall conditions. PIP measurements similarly were averaged over matching time periods for consistency in method. Through the remainder of this article, we use the term PSD to refer to both particle size histograms measured by the MASC and the conventional PSDs measured by the PIP.

Uncertainties in the calculated MASC slope parameters were quantified as in $\mathrm{C} 17$. These uncertainty terms consider both the quality of the slope regression fit as well as expected uncertainties in MASC estimates of particle size from a study by Kleinkort et al. (2017). Uncertainties in the PIP slope parameter were based upon goodness of fit of the regression. Typical values of slope parameter are approximately $2-3 \mathrm{~mm}^{-1}$ with uncertainties less than $0.2 \mathrm{~mm}^{-1}$ for this study. Because of the small uncertainties found for the observed MASC and PIP slope parameters, uncertainties in $N_{0}$ were allowed to be large (C17). Thus, the number of particles could vary so that forward modeled simulated reflectivities were able to match the observed reflectivities and the retrieval could converge.

As an alternate assumption to the MASC and PIP observations, temperature-dependent values of PSD $\lambda$ and $N_{0}$ from Wood (2011) were also explored in the retrieval algorithm. This temperature-dependent PSD parameterization is potentially useful either when we do not have in situ observations or when we suspect biases in the observations.

Defining the relationship between particle dimension, mass, and backscattering properties (a snow particle model) is essential to radar-based snowfall retrievals, and uncertainties in particle models are a significant source of retrieval uncertainty (C17). We used MASC observations of snowflake habit at the Haukeliseter site to guide this choice. Since we saw predominately aggregates, we focus here on two aggregate particle models developed for the CloudSat mission, B6pf and B8pr-30, which had markedly different maximum dimension-backscatter relationships. Please see Wood et al. (2015) for a more thorough description of these particle models. The B6pf will hereafter be referred to as the "reflective aggregate" (RA) particle as it produced high reflectivities per unit mass relative to the B8pr-30, hereafter designated as the "less reflective aggregate" (LRA) particle. Scattering properties for these particle models were calculated using DDA for the $24-\mathrm{GHz}$ frequency.

\section{Snow particle microphysical properties}

A primary goal of HiLaMS was to define how snow microphysical properties and snowfall retrieval performance vary as a function of storm regime at meteorologically distinct high-latitude sites. In this section, we present observations of PSD metrics, particle fall speeds, and snowflake habits as collected over the course of the 2016/17 season at Haukeliseter.

\section{a. Snow event classification}

An analysis of MRR reflectivities and basic meteorological observations suggested that the majority of the snowfall was the product of two distinct snow regimes at the Haukeliseter Test Site during winter 2016/17, as shown in Figs. 3 and 4. The first storm type was associated with continuous, moderate snowfall. These events typically had MRR reflectivities near $15-20 \mathrm{~dB}_{e}$ and light winds generally below $6 \mathrm{~m} \mathrm{~s}^{-1}$ and from the southeast, as seen in a wind rose analysis in Fig. 5. From the topographic map of Haukeliseter shown in the right panel of Fig. 1, this wind direction suggests gently lifting air as it flows up the eastern flank of the mountain ridge. 

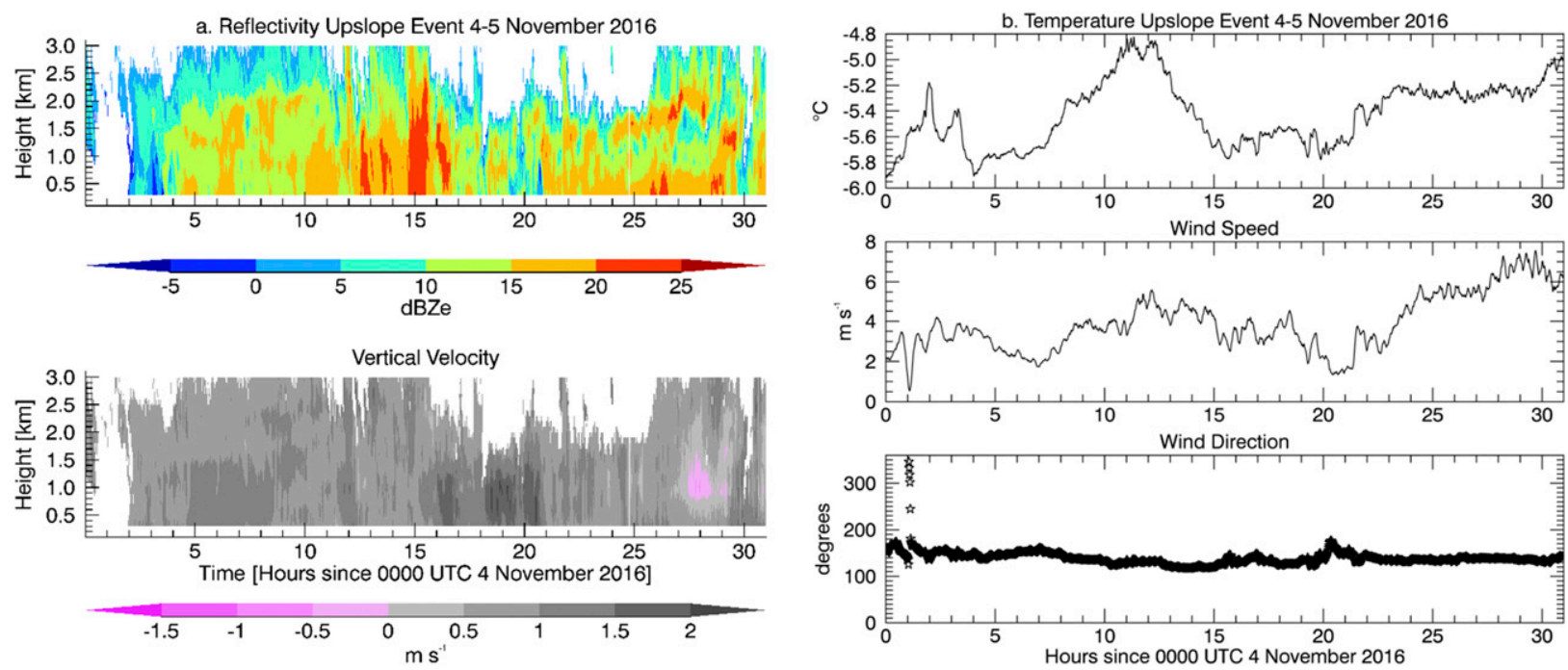

FIG. 3. MRR and meteorological data for an upslope event on 4-5 Nov 2016. (a) Time series of MRR (top) reflectivity and (bottom) vertical velocity. (b) Time series of (top) temperature, (middle) wind speed, and (bottom) wind direction.

As such, these events will be referred to as "upslope" events.

The second storm regime exhibited repeated pulses of heavy snowfall that typically lasted around $30-45 \mathrm{~min}$ and alternated with similar durations of light to no snowfall. MRR reflectivities were typically greater than $25 \mathrm{~dB} Z_{e}$ for the periods of heavy snowfall but were less than $15 \mathrm{~dB} Z_{e}$ for the light snow periods. Winds speeds were very often above $9 \mathrm{~m} \mathrm{~s}^{-1}$ but could exceed $20 \mathrm{~m} \mathrm{~s}^{-1}$ for strong events. During these events, wind tended to originate from the west (between $260^{\circ}$ and $280^{\circ}$ ) as seen in Fig. 5. From the topographic map in Fig. 1, this direction indicates airflow coming from the direction of the fjords and mountains to the west of Haukeliseter and would be consistent with the presence of wave breaking and gravity waves on the lee side of the ridge. Such behavior would explain the pulsed nature of these storms, which hereafter will be referred to as "pulsed."

MASC data were available for 4 upslope regime cases and 6 pulsed regime cases between November 2016 and December 2016, providing information from approximately 250000 snowflakes. PIP data were available for 10 upslope regime cases and 9 pulsed regime cases between December 2016 and February 2017. Over the course of these events, we observed approximately $100 \mathrm{~mm}$ of LWE of upslope precipitation and $175 \mathrm{~mm}$ LWE of pulsed precipitation as measured by the Haukeliseter DFAR.

\section{b. Snowflake habit}

MASC images suggested that the vast majority of particles produced during both upslope and pulsed events were rimed aggregates as shown in Fig. 6. Visual inspection was corroborated with calculated mean complexity values of 1.52 and 1.50 for upslope and pulsed storms, respectively, which are indicative of rimed particles (Garrett and Yuter 2014). Pristine crystal types were very rarely seen at the surface. It is possible both storm regimes exhibited similar rimed aggregate particle structure because of the high liquid water content that might be expected in the Norwegian coastal mountains. As such, we chose the RA as the particle model assumption for both storm regimes. This compact, reflective aggregate model can produce the large backscatters one might expect from snow particles entrained in a high liquid water content environment aloft.

\section{c. Snow particle size distributions}

MASC and PIP observations were analyzed to estimate both mean particle size and slope parameter by storm regimes using the approaches described in section $2 \mathrm{c}$ (see Table 1). The values presented here represent the averages of the individual PSD values found for each storm case for each storm category. Both MASC and PIP observations suggest that pulsed events are associated with particles with smaller mean maximum dimension (i.e., the mean of the maximum particle dimensions of all observed particles for a given data subset) than upslope events. The MASC found mean maximum values of 0.79 and $0.70 \mathrm{~mm}$ for the upslope and pulsed regimes, respectively. The PIP found mean maximum values of 0.73 and $0.60 \mathrm{~mm}$ for the upslope and pulsed regimes, respectively. Wind speed, however, may be a confounding factor for these results. Overall, particle dimension decreased with increasing wind 

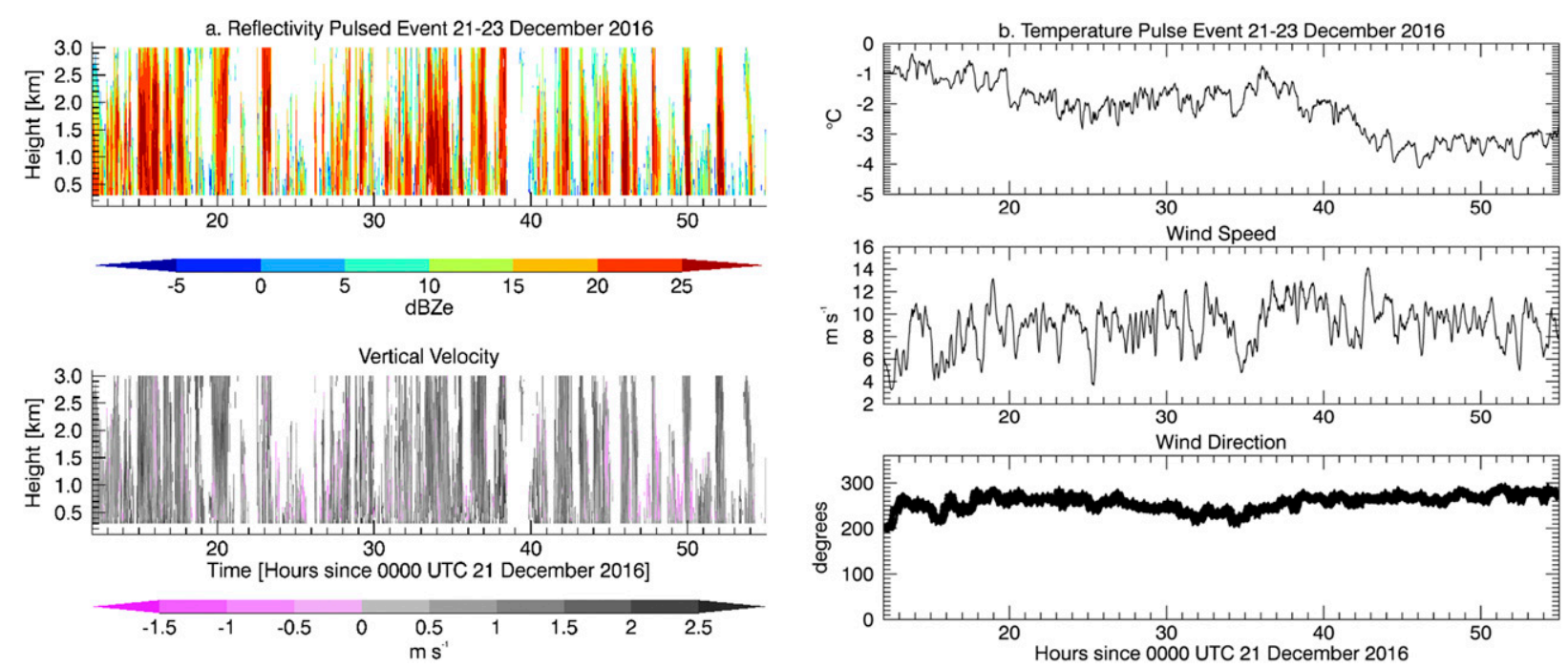

FIG. 4. MRR and meteorological observations for a pulsed event on 21-23 Dec 2016. (a) Time series of MRR (top) reflectivity and (bottom) vertical velocity. (b) Time series of (top) temperature, (middle) wind speed, and (bottom) wind direction.

speed, and pulsed events were significantly windier than upslope events. This wind-size relationship possibly could be driven by the presence of small blowing snow particles during the stronger wind events. This is a topic we will return to in the discussion of snowfall retrievals in sections 4 and 5 .

Understanding the differences between MASC and PIP estimates of PSD is important as they will translate into differences in retrieved MRR snowfall rates and calculated accumulation values. Figure 7 shows a typical plot of PSD observations for a snow event that transitioned from pulsed to upslope conditions on 23 December. The MASC very rarely measured particles over $2.5 \mathrm{~mm}$, whereas the PIP routinely saw particles greater than $5 \mathrm{~mm}$ and sometimes over $10 \mathrm{~mm}$ for both regimes. These largest snowflakes in the tail of the distribution are key when performing the exponential fit to derive slope parameter. And given that radar reflectivity is most sensitive to the largest particles, the accurate description of the PSD tail is critical when estimating snowfall rates from MRR observations.

MASC-derived slope parameters therefore were larger than those found from the PIP, where larger slope parameters denote a decreased width in the particle distribution and smaller particles. MASC and PIP slope parameters values were 2.61 and $2.29 \mathrm{~mm}^{-1}$, respectively, for upslope events. MASC and PIP slope parameters values were 3.32 and $3.01 \mathrm{~mm}^{-1}$, respectively, for pulsed events.
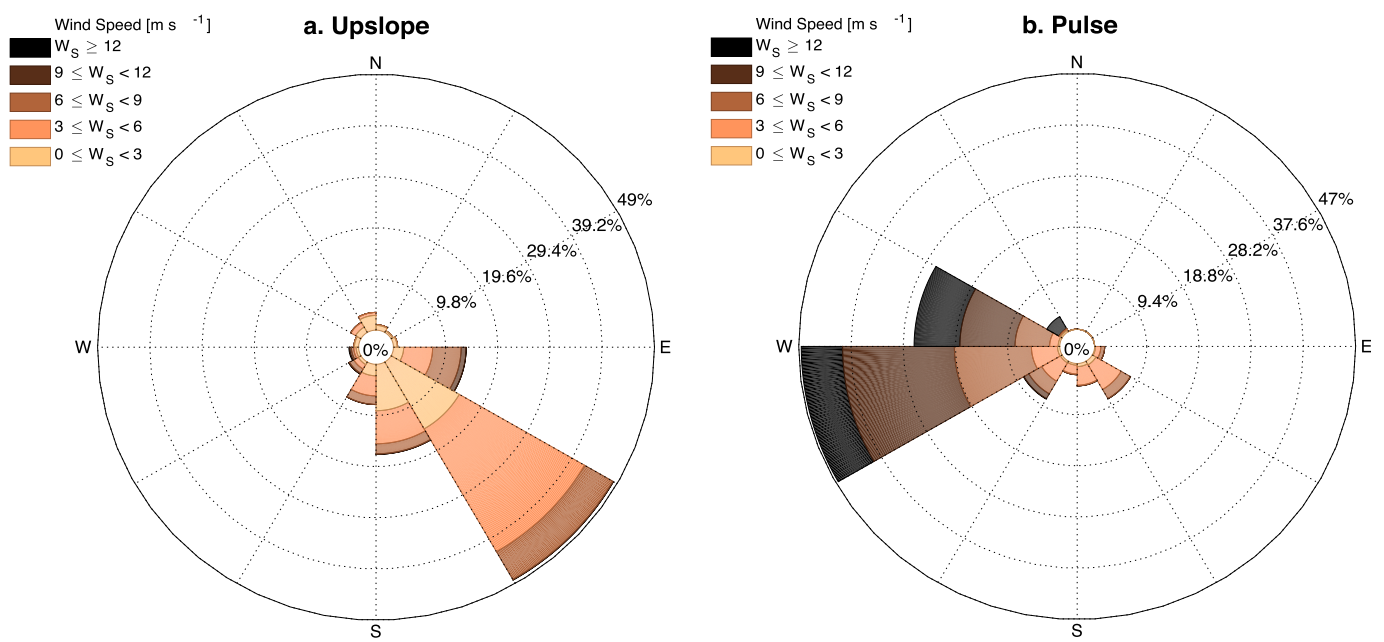

FIG. 5. Wind roses for the (a) upslope and (b) pulsed snowfall regimes observed during HiLaMS. 


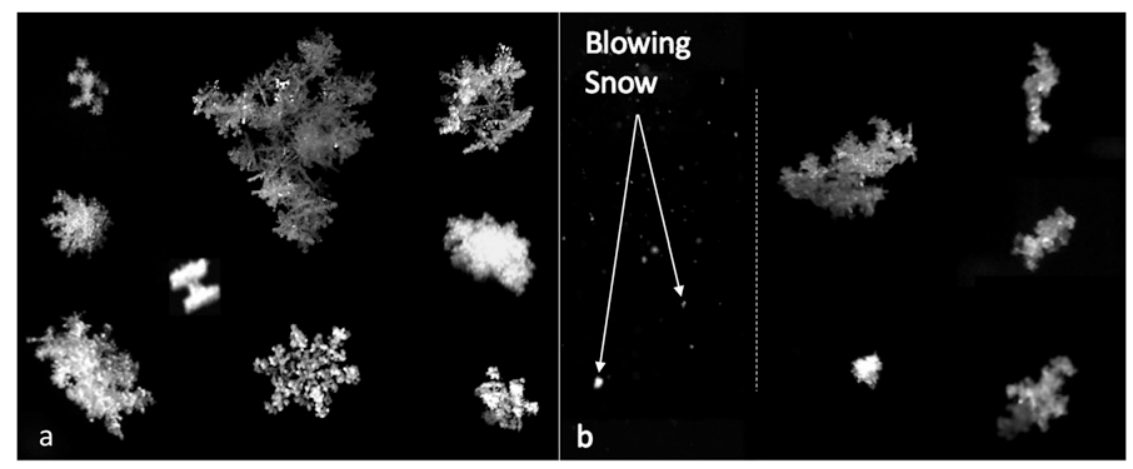

FIG. 6. (a) Typical snowflake habits observed during upslope storm events. (b) (left) An image of likely blowing snow particles that predominate MASC images during pulsed events. The white arrows point to two of the many blowing snow particles contained in the image. (right) Examples of large precipitating crystals observed during the pulsed events.

These analyses also may provide insight into possible sampling biases of the instruments as deployed at the Haukeliseter site. The PIP captures videos of snowflakes as they pass relatively unobstructed through the 2-m distance between the camera and lamp as shown in Fig. 2. In contrast, snowflakes must not only pass through the comparatively small MASC housing ring but also trigger the near-infrared sensors in the center of sampling volume to activate the MASC cameras. For snow events with horizontal winds, large aggregates may have such inertia that they simply cannot enter the MASC sampling ring even if the wind streamlines do. Such conditions would bias MASC measurements small as suggested by the lack of larger particles in Fig. 7 for both upslope and pulsed conditions. It is also possible that the reduced sampling volume of the MASC relative to the PIP led to insufficient characterization of the ambient large particles at the tail of the distribution. To counter such a potential bias, to the extent possible, we generated PSD by averaging over entire storm subsections as described in section 2.

The values presented for storm type PSD parameters above were based upon averaging over entire storms within each regime. However, MRR reflectivities as shown in Figs. 3 and 4 indicate distinctive structures within the storms, for example, the pulsed storms alternate periods of high and low reflectivity. It seems possible that these distinct storm sections with different reflectivities and atmospheric motions might also exhibit different snow particle microphysics. As such, we performed a similar analysis as above but broken down as a function of reflectivity, for example, $<15,15-20$, 20-25, and $>25 \mathrm{~dB} Z_{e}$.

Table 2 lists the slope parameters found from both the MASC and PIP for upslope and pulsed events for these reflectivity thresholds. The PIP observations show a steady decrease in slope parameter (increase in the width of PSD) as reflectivity increases for both upslope and pulsed conditions. This trend is consistent with the generation of larger snowflakes during more intensely precipitating segments of the storm. The MASC also finds decreasing slope parameter with increasing reflectivity for the pulsed events. However, the MASC sees the opposite for the upslope events in that slope parameters increase with increasing reflectivity. Such results seem counterintuitive, as we would expect larger particles for higher reflectivity conditions, and may indicate a potential bias in the measurements.

\section{d. Fall speed measurements}

Accurate estimates of snowflake fall speed are essential to our snowfall algorithm as they translate SWC aloft into a surface snowfall accumulation rate. The HiLaMS campaign provided three independent observations of

TABLE 1. Slope parameters $\left(\lambda, \mathrm{mm}^{-1}\right)$ with uncertainties, mean maximum dimension, and mean fall speed as observed by the MASC and PIP for all upslope and pulsed storms.

\begin{tabular}{lcccc}
\hline \hline & $\lambda\left(\mathrm{mm}^{-1}\right)$ & $\lambda$, uncertainty $\left(\mathrm{mm}^{-1}\right)$ & Mean $D_{M}(\mathrm{~mm})$ & ${\text { Mean fall speed }\left(\mathrm{m} \mathrm{s}^{-1}\right)}$ \\
\hline MASC upslope & 2.61 & 0.12 & 0.79 & 0.86 \\
MASC pulsed & 3.32 & 0.10 & 0.70 & 0.99 \\
PIP upslope & 2.29 & 0.11 & 0.73 & 0.71 \\
PIP pulsed & 3.01 & 0.10 & 0.60 & 0.09 \\
\hline
\end{tabular}



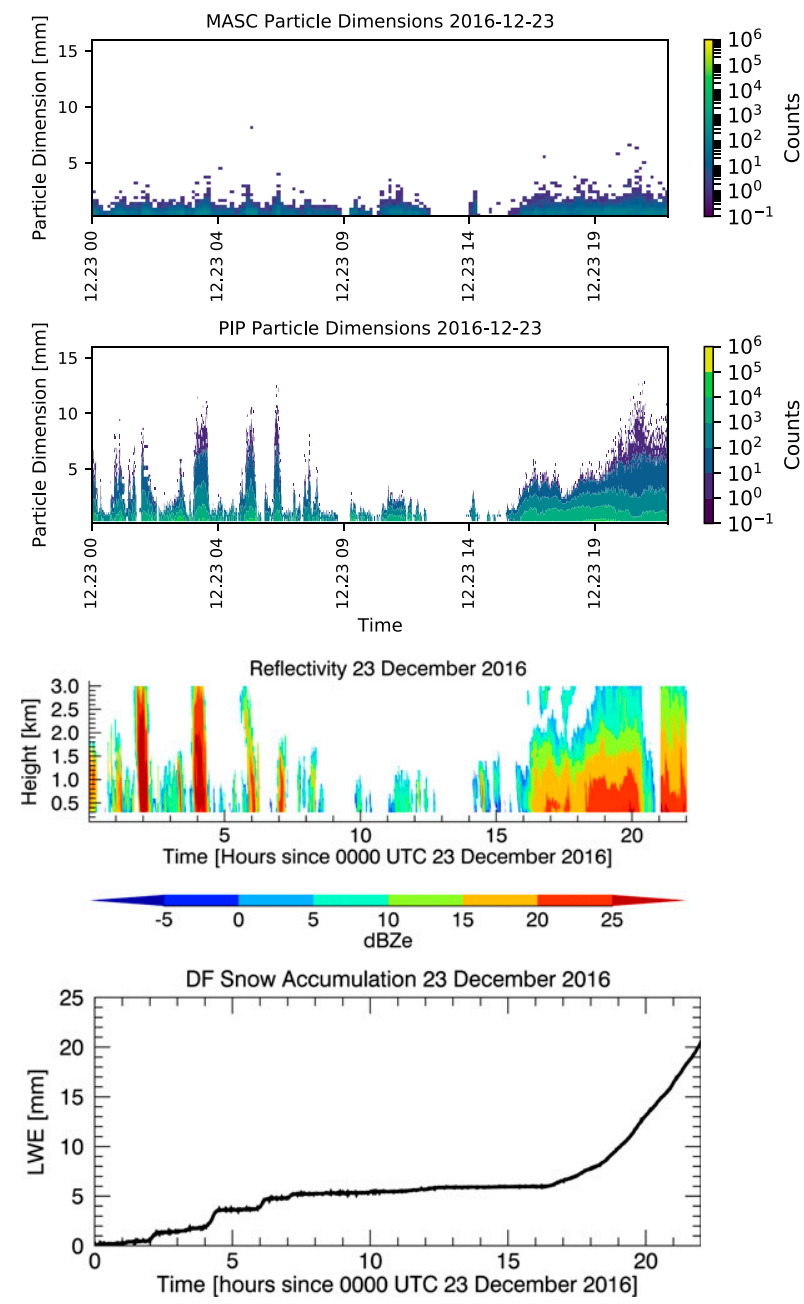

FIG. 7. (top two panels) MASC- and PIP-observed particle size distributions for a $23 \mathrm{Dec}$ snow event. (bottom two panels) MRR reflectivity and accumulated snowfall totals from the Met Norway DFAR, respectively. The storm transitioned from a pulsed event to an upslope event around 1400 UTC. Note that the low reflectivity part of the storm around 2100 UTC may have been caused by performance issues with the MRR. The continuous snowfall measured by the DFAR during this time does not suggest such a storm lull.

fall speed, one each from the MASC, PIP, and MRR Doppler velocity measurements. These observations represent a combination of the particles' natural terminal velocities imprinted upon the ambient atmospheric motion and turbulence created at the Haukeliseter site during the storm events. The in situ instruments may further complicate the observations by disrupting airflow during the sampling process itself as discussed previously. For our analyses, we focused on fall speed as a function of storm type for the reasons discussed above and for lack of any clear observed correlation between particle size and fall speed.

Figure 8 shows the distribution of MASC- and PIPobserved fall speeds for both storm types. The mean MASC-observed fall speeds for upslope and pulsed were 0.86 and $0.99 \mathrm{~m} \mathrm{~s}^{-1}$, respectively. The mean PIPobserved fall speeds for upslope and pulsed were 0.72 and $0.10 \mathrm{~m} \mathrm{~s}^{-1}$, respectively. These differences in MASC and PIP fall speeds may be linked to the sampling methods of each. The MASC, by design, only can measure positive fall speeds (downward motion) as the particles must fall through the sampling ring to trigger the IR sensor estimates of fall speed. The PIP can measure positive and negative fall speeds (upward motion) as the snowflakes pass unobstructed through the field of view of the video camera.

The distribution of fall speeds observed by the PIP is much wider than that that observed by the MASC and includes significant negative fall speeds for both upslope and pulsed events. Within these PIP observations, the pulsed storms exhibited both larger negative fall speeds and a higher fraction of negative fall speeds than the upslope storms. The low average value of $0.10 \mathrm{~m} \mathrm{~s}^{-1}$ observed during pulsed events likely was due to the cancelling effects of the positive and negative fall speeds integrated over time. In contrast, for the upslope events, the average fall speed for the PIP $\left(0.72 \mathrm{~m} \mathrm{~s}^{-1}\right)$ was much closer to the value found by the MASC $\left(0.86 \mathrm{~m} \mathrm{~s}^{-1}\right)$.

The mean MRR Doppler velocities for the lowest nonnoise radar bin $\left(\sim 300 \mathrm{~m}\right.$ AGL) were $0.97 \mathrm{~m} \mathrm{~s}^{-1}$ for pulsed storms and $1.15 \mathrm{~m} \mathrm{~s}^{-1}$ for upslope events. The lower Doppler velocity for the pulsed versus upslope storms likely arises from the presence of strong updrafts in the pulsed storms. Negative fall speeds occur about $25 \%$ of the time between 300 and $800 \mathrm{~m}$ AGL in pulsed events but only $8 \%$ of the time during upslope storms.

Fall speeds derived from the MRR, PIP, and MASC also were analyzed as a function of reflectivity threshold

TABLE 2. Observed slope parameters $\left(\mathrm{mm}^{-1}\right)$ for a fitted exponential size distribution as a function of reflectivity.

\begin{tabular}{lcccc}
\hline \hline & MASC upslope & MASC pulsed & PIP upslope & PIP pulsed \\
\hline$<15 \mathrm{~dB} Z_{e}$ & 2.56 & 3.62 & 2.82 & 3.68 \\
$15-20 \mathrm{~dB} Z_{e}$ & 2.79 & 3.38 & 2.33 & 3.18 \\
$20-25 \mathrm{~dB} Z_{e}$ & 2.84 & 3.28 & 2.26 & 2.78 \\
$>25 \mathrm{~dB} Z_{e}$ & 3.09 & 3.14 & 1.86 & 2.64 \\
Overall & 2.61 & 3.32 & 2.29 \\
\hline
\end{tabular}




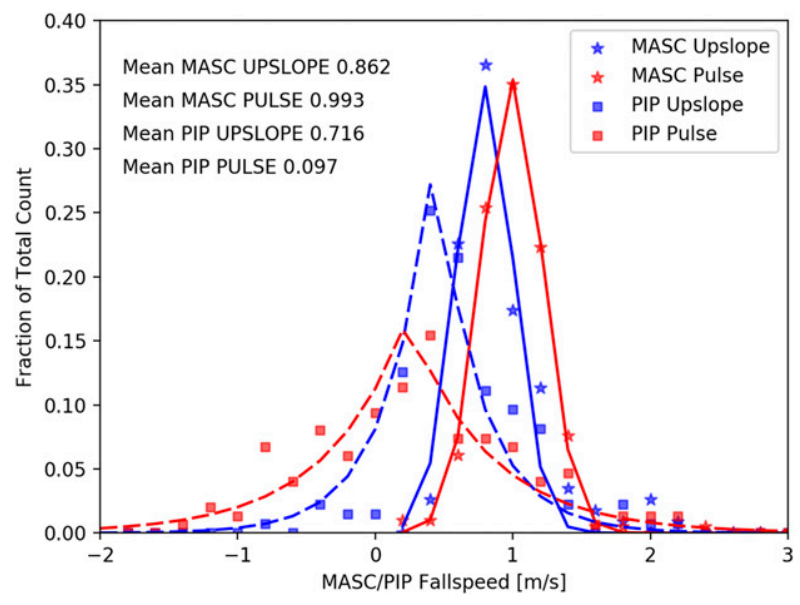

FIG. 8. Normalized fall speed distributions as observed by the MASC and PIP for both upslope and pulsed snow events.

categories as applied previously for each storm type as shown in Table 3. For the pulsed events, both the MRR and MASC saw increases in fall speed with increased reflectivity. Such a relationship is consistent with larger and heavier particles that both fall faster and produce higher reflectivities. PIP observations also show a general increase in fall speed with reflectivity for this storm type. The small and sometimes even negative average fall speed values for the lowest reflectivity categories highlight the importance of turbulence for the pulsed events.

For the upslope events, the MASC also measured increasing fall speeds with increasing reflectivity. Such a result would be consistent with increased vertical motions during the stronger parts of the storm. Or it could be that the higher fall speeds were associated with larger and heavier particles that produced higher reflectivities. This latter hypothesis, however, is inconsistent with the finding of smaller particles with increasing reflectivity for this storm type as discussed in section 3c. Both the MRR and PIP found relatively uniform fall speeds with reflectivity for the low wind events. Doppler velocities, however, were larger than the near-surface fall speed observations from the MASC or PIP. This result could arise if particles aloft are moderated by surface turbulence as they settle near the ground. Or it could be that the Doppler velocity signal is weighted by larger particles that fall faster than the smaller mean particle sizes seen by the MASC or PIP.

\section{Snowfall retrieval applications}

Observations of snow PSDs, fall speeds, and particle habit discussed in section 3 were incorporated into our MRR-based optimal-estimation retrieval scheme to obtain estimates of surface snowfall rate. We present case studies for a typical upslope and pulsed snow events at the Haukeliseter Test Site. These analyses highlight our general retrieval technique, quantify sensitivity of retrieval results to key input parameters, and illustrate differences for the two storm types. Retrieval performance is evaluated through calculation of differences and Pearson correlation coefficients (PCC) between retrieved estimates of snowfall and the Met Norway DFAR observations as a function of storm type. When evaluating these comparisons, it is important to recall that studies have found typical mean undercatchment values of $10 \%$ during moderate wind speed events (i.e., less than $10 \mathrm{~m} \mathrm{~s}^{-1}$; Yang 2014) for the DFIRs similar to that at the Haukeliseter Test Site. For all retrievals, a $1^{\circ} \mathrm{C}$ temperature threshold value was used to distinguish between frozen and nonfrozen precipitation scenes.

\section{a. 4-5 November upslope test case}

Our first case study was an upslope event that occurred over 4-5 November 2016. Figure 3 shows plots of MRR reflectivity, Doppler velocity, temperature, wind speed and wind direction observations during the 31-h period starting at 0000 UTC 4 November 2016. Snow developed around 0200 UTC 4 November 2016 and continued through the late hours of 5 November 2016. The temperature remained fairly steady between $-5^{\circ}$ and $-6^{\circ} \mathrm{C}$ for the event period. The winds were from the southeast with speeds below $6 \mathrm{~m} \mathrm{~s}^{-1}$ for nearly the entire event, typical of the upslope storm regime. MASC data were available for this event but PIP data were not. Table 4 lists the event-specific PSD $\lambda$ and fall speed observations used as retrieval assumptions as a function of reflectivity category.

Retrieved estimates of surface snowfall found using different retrieval assumption permutations for this

TABLE 3. Average observed fall speeds $\left(\mathrm{m} \mathrm{s}^{-1}\right)$ as a function of MRR reflectivity observations.

\begin{tabular}{lcccccc}
\hline \hline & MASC upslope & MASC pulsed & PIP upslope & PIP pulsed & MRR $V_{D}$ upslope & MRR $V_{D}$ pulsed \\
\hline$<15 \mathrm{~dB} Z_{e}$ & 0.81 & 0.82 & 0.68 & -0.033 & 1.20 & 0.92 \\
$15-20 \mathrm{~dB} Z_{e}$ & 0.79 & 0.96 & 0.73 & -0.19 & 1.10 & 0.94 \\
$20-25 \mathrm{~dB} Z_{e}$ & 0.86 & 1.01 & 0.76 & 0.078 & 1.09 & 1.03 \\
$>25 \mathrm{~dB} Z_{e}$ & 0.93 & 1.16 & 0.69 & 0.19 & 1.15 & 0.97 \\
Overall & 0.86 & 0.99 & 0.72 & 0.10 & & 1.15 \\
\hline
\end{tabular}


TABLE 4. Observed slope parameters $\left(\lambda, \mathrm{mm}^{-1}\right)$ and fall speed $\left(\mathrm{m} \mathrm{s}^{-1}\right)$ as a function of reflectivity for a 4-5 Nov upslope snow event and a 21-23 Dec pulsed snow event.

\begin{tabular}{lcccccc}
\hline \hline & $\begin{array}{c}\text { MASC } \lambda\left(\mathrm{mm}^{-1}\right) \\
\text { upslope }\end{array}$ & $\begin{array}{c}\text { MASC } V\left(\mathrm{~m} \mathrm{~s}^{-1}\right) \\
\text { upslope }\end{array}$ & $\begin{array}{c}\text { MASC } \lambda\left(\mathrm{mm}^{-1}\right) \\
\text { pulsed }\end{array}$ & $\begin{array}{c}\text { MASC } V\left(\mathrm{~m} \mathrm{~s}^{-1}\right) \\
\text { pulsed }\end{array}$ & $\begin{array}{c}\text { PIP } \lambda\left(\mathrm{mm}^{-1}\right) \\
\text { pulsed }\end{array}$ & $\begin{array}{c}\text { MRR } V_{\text {DOP }}\left(\mathrm{m} \mathrm{s}^{-1}\right) \\
\text { pulsed }\end{array}$ \\
\hline$<15 \mathrm{dBZ}_{e}$ & 1.24 & 0.72 & 4.64 & 0.83 & 4.47 & 1.22 \\
$15-20 \mathrm{~dB} Z_{e}$ & 2.19 & 0.62 & 3.72 & 0.97 & 3.57 & 1.22 \\
$20-25 \mathrm{~dB} Z_{e}$ & 2.46 & 0.61 & 3.51 & 1.04 & 2.76 & 1.26 \\
$>25 \mathrm{~dB} Z_{e}$ & 2.66 & 0.41 & 3.33 & 1.20 & 2.45 & 1.30 \\
\hline
\end{tabular}

upslope event are plotted in Fig. 9 along with Met Norway DFAR and single fence gauge accumulation measurements. The use of in situ MASC PSD and fall speed observations with the RA particle model yielded a snowfall accumulation with a difference of $-18.8 \%$ relative to the DFAR. The PCC was 0.86 , indicating a strong linear relationship between MRR snowfall estimate and DFAR observations (PCCs were calculated using half hourly snowfall totals). These results contrast with those found using the LRA particle model, which produced a $+64 \%$ increase in snowfall relative to use of the RA model with fixed fall speed and PSD $\lambda$.

To explore the sensitivity of the retrieval scheme to $\operatorname{PSD} \lambda$, we performed the retrieval with the temperaturebased PSD parameterization with MASC fall speed and the RA model. Figure 9 shows that this curve nearly matches that produced using the MASC PSD $\lambda$ with fixed fall speed and RA particle model. This suggests that the choice of PSD $\lambda$ between these retrieval options has a relatively small impact on retrieved snowfall rates for this upslope event. This result may change for higher reflectivity events (i.e., pulsed) or perhaps even for much colder snow events. But, this minimal sensitivity is encouraging given the potential sampling biases in our PSD observations.

To illustrate the sensitivity of the scheme to fall speed, we used assumptions of MRR Doppler velocity with temperature-dependent PSD and RA particle model. This combination produced a snowfall accumulation $+80 \%$ greater than when assuming the MASC fall speed observations with fixed PSD and particle habit as shown in Fig. 9. This shows fall speed can have a large impact on snowfall estimates, although these results were particularly exacerbated for this case as MASC fall speeds were unusually low during this storm.

Overall, the use of the various retrieval assumptions in Fig. 9 led to differences ranging from $-24 \%$ to $+38 \%$ relative to the DFAR for this event. These values and the sensitivities to particle model, PSD, and fall speed all agree to the first order with results from $\mathrm{C} 17$. We also highlight that the DFAR measured more than twice as much snow LWE than the single fence snow gauge. This trend is consistent across all frozen precipitation events during HiLaMS and stresses the need for use of the DFAR for validation even for low wind events (typical winds less than $6 \mathrm{~m} \mathrm{~s}^{-1}$ for these storms).

\section{b. 21-23 December pulsed test case}

Our second test case was a pulsed event from 1200 UTC 21 December through 0500 UTC 23 December 2016. Figure 4 shows a time series of MRR reflectivities, Doppler velocities, temperature, wind speed and direction for this pulsed event. The winds during this storm were generally above $8 \mathrm{~m} \mathrm{~s}^{-1}$ and were primarily from the west with a mode wind direction of $270^{\circ}$. For this storm, both MASC and PIP data were available. Table 4 lists PSD $\lambda$ and fall speed observations used as retrieval assumptions for this event as a function of reflectivity category.

Retrieved estimates of surface snowfall using different retrieval assumptions for this pulsed event are plotted in Fig. 10 along with DFAR and single fence gauge snow measurements. Estimates of snowfall found

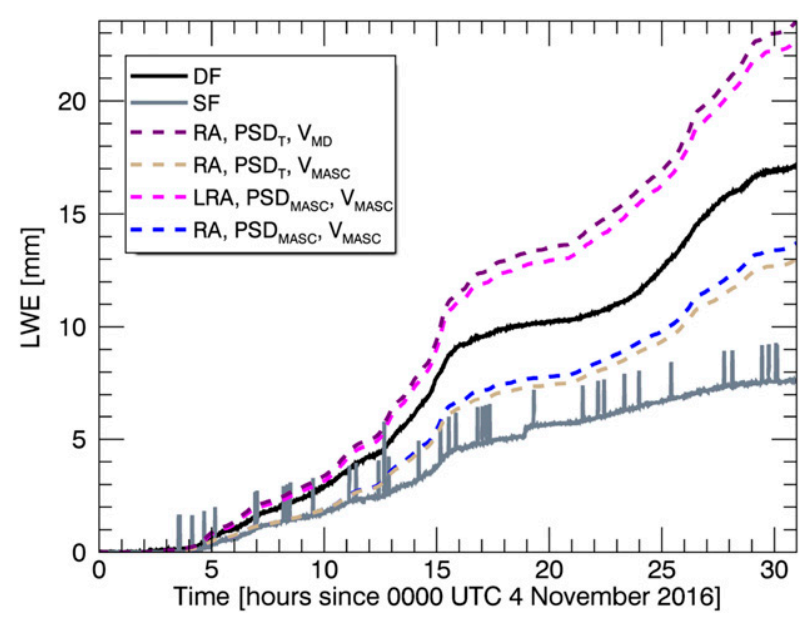

FIG. 9. Retrieved snowfall rates (LWE) using different retrieval assumptions are plotted against Met Norway snow gauge observations for a typical upslope event. DF and SF refer to the DFAR and single fence snow gauge, respectively. RA and LRA refer to snowflake particle models as described in text. PSD $_{T}$ and PSD $_{\text {MASC }}$ refer to slope parameters derived from the temperature-dependent parameterization and MASC observations, respectively. $V_{\mathrm{MD}}$ and $V_{\text {MASC }}$ refer to fall speed metrics taken from MRR Doppler velocity and MASC observations, respectively. 


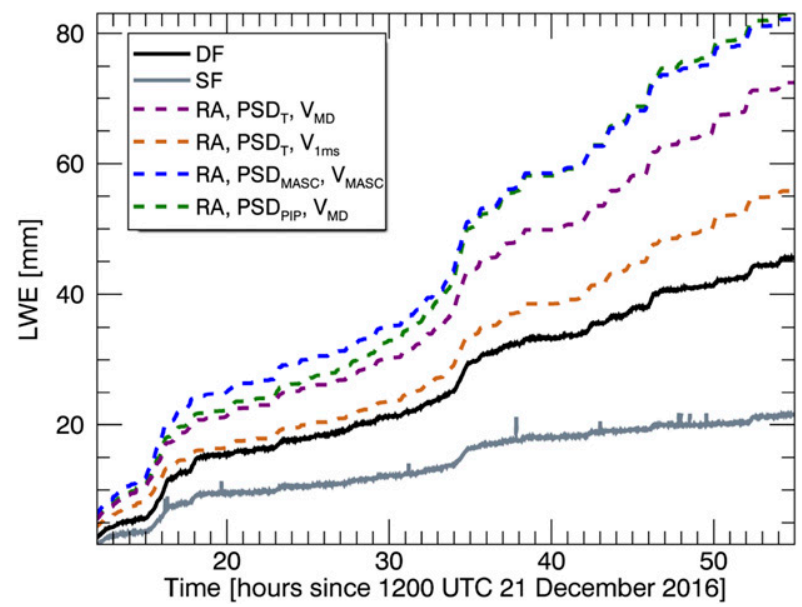

FIG. 10. Retrieved snowfall rates (LWE) using different retrieval assumptions are plotted against Met Norway snow gauge observations for a typical pulsed event. PSD $_{\text {PIP }}$ refers to slope parameter as derived from the PIP. $V_{1 \mathrm{~ms}}$ refers to a fall speed assumption of $1 \mathrm{~m} \mathrm{~s}^{-1}$. All other labels are defined as in Fig. 9.

using the MASC PSD $\lambda$ and fall speed with the RA particle did not agree well with DFAR accumulation with a $+77 \%$ difference. Interestingly, the PCC was 0.89 , suggesting there is still a strong linear relationship between the two. Use of the LRA model used in the CloudSat retrieval scheme with the MASC microphysical observations suggested snowfall accumulations in excess of $200 \%$ of the DFAR.

We did not perform parallel calculations using the PIP as observed fall speeds were often very small or negative given the near-surface turbulence in these pulsed storms even when averaged over time. As an alternate metric, we used the MRR Doppler velocity at $\sim 300 \mathrm{~m}$ AGL as it should suffer less from surface-forced turbulence than the PIP fall speed observations. Use of the PIP and MRR assumptions with the RA particle led to a $+80.3 \%$ difference relative to the DFAR with a PCC of 0.89 .

The use of in situ MASC and PIP PSD $\lambda$ clearly results in overestimates snowfall for this event regardless of fall speed assumption. MASC images for these windy events very often observed bits and shards of individual crystals that would be consistent with blowing snow, as shown in Fig. 6. These particles likely are not representative of the precipitating snowflakes observed by the MRR aloft. The use of too-small particles in a retrieval scheme should bias results high, as the retrieval must produce more SWC to match observed MRR reflectivities than it would with the assumption of larger particles.

The best agreement with the DFAR for this case came with use of the temperature-dependent PSD parameterization developed for the CloudSat 2C-SNOW-PROFILE retrieval. Use of this a priori PSD relationship with either a constant $1 \mathrm{~m} \mathrm{~s}^{-1}$ or MRR Doppler velocity as fall speed with the RA model resulted in differences of $+20.0 \%$ and $+56.2 \%$, respectively, for this event. This parameterization suggested larger particles and thus smaller slope parameters $\left(1.68 \mathrm{~mm}^{-1}\right)$ than those found from either the MASC $\left(3.56 \mathrm{~mm}^{-1}\right)$ or PIP $\left(3.00 \mathrm{~mm}^{-1}\right)$. In other words, use of meteorological expectations for particle size produced better results than our likely biased PSD observations for this windy and turbulent snow event. Note that the $1.68 \mathrm{~mm}^{-1}$ value agrees well in spirit with a slope parameter of $1.02 \mathrm{~mm}^{-1}$ presented in Wood et al. (2014) for a similar heavy snowstorm case.

\section{Retrieval statistics for the field season}

In this section, we apply our snowfall retrieval scheme over all observed snow events during the HiLaMS Haukeliseter deployment. These analyses not only quantify performance of the snowfall retrieval scheme over the course of the season but also explore the expected range of uncertainties in retrieved snowfall for individual snow events. These seasonal cumulative statistics were calculated from snowfall estimates for 15 upslope cases and 14 pulsed cases with a combined total of nearly $300 \mathrm{~mm}$ total LWE, according to the DFAR. For the MASC and PIP observations, we used the reflectivity-dependent values for PSD $\lambda$ and fall speed as outlined in Tables 2 and 3 .

\section{a. Upslope retrieval statistics}

Table 5 presents snowfall accumulation statistics found using different retrieval assumptions for all upslope events observed during HiLaMS. The use of in situ observations with the RA model resulted in retrieved estimates of snowfall that agreed well with the DFAR. Using the MASC PSD $\lambda$ and fall speed values resulted in a $+9.0 \%$ cumulative difference over the entire season with a mean absolute percentage error (MAPE) for the individual snow events of $34.9 \%$. The PCC was 0.83 when applied to half hour intervals. Using the PIP PSD $\lambda$ and fall speed values resulted in closer agreement with a $-0.4 \%$ cumulative difference over the entire season and a MAPE of $32.9 \%$.

These results contrast with those found using the LRA model. Use of in situ PSD $\lambda$ and fall speed observations with this particle model led to seasonal snowfall accumulation differences of $+79 \%$ and $+59 \%$ with the DFAR for the MASC and PIP, respectively. The corresponding MAPEs were $89.3 \%$ and $70.4 \%$, indicating consistently large errors for individual storm events. As with the upslope test case, it appears that the particle model that worked well in Barrow for the test cases described in $\mathrm{C} 17$ does not perform well for the meteorological conditions at Haukeliseter. 
TABLE 5. Differences in cumulative snowfall accumulation found between snowfall retrievals with the given assumptions and the Met Norway DFAR for all upslope events during HiLaMS. MAPE defines the mean absolute percentage error for the individual snow events. PCC is the Pearson correlation coefficient between snowfall retrievals and DFAR calculated for half-hour interval accumulation values. When evaluating these comparisons, it is important to recall that studies have found typical mean undercatchment values of $10 \%$ for snow gauges similar to those at the Haukeliseter Test Site (Yang 2014).

\begin{tabular}{|c|c|c|c|c|c|}
\hline Particle model & PSD & Fall speed & $\%$ difference & MAPE & PCC \\
\hline Reflective (RA) & MASC & MASC & +9 & 34.9 & 0.83 \\
\hline Reflective (RA) & PIP & PIP & -0.4 & 32.9 & 0.83 \\
\hline Less reflective (LRA) & MASC & MASC & +78.7 & 89.4 & 0.82 \\
\hline Less reflective (LRA) & PIP & PIP & +59.4 & 70.4 & 0.82 \\
\hline Reflective (RA) & Temperature-based & Doppler velocity & +27.3 & 40.4 & 0.82 \\
\hline
\end{tabular}

Given potential biases with the in situ observations, we also considered retrieval forms in which the snowflake microphysical information was not derived from either the MASC or PIP. For example, use of the temperature-based parameterization of PSD $\lambda$ and MRR Doppler velocities as a fall speed metric with the RA model resulted in seasonal snowfall accumulation differences with the DFAR of $+27.3 \%$ with a MAPE of $40.4 \%$. These differences are only slightly larger than those found using the MASC and PIP in situ observations.

\section{b. Pulsed retrieval statistics}

Table 6 presents snowfall accumulation statistics found using different retrieval assumptions for all pulsed events observed during HiLaMS. Similar to the pulsed case study results, use of in situ observations with the RA model resulted in poor agreement with the DFAR values over the season. Specifically, using the MASC PSD $\lambda$ and fall speed values resulted in a $+48.9 \%$ cumulative difference over the entire season with a MAPE for the individual snow events of $52.7 \%$. Use of the LRA particle with MASC in situ assumptions led to even more substantial differences $(+139 \%)$ between retrieval results and DFAR.

As before, we cannot perform a similar meaningful analysis with the PIP data given the frequent negative fall speeds observed by the PIP. However, incorporating Doppler velocity as a fall speed metric from the nearest surface bin with the PIP PSD $\lambda$ and RA model in the retrieval scheme resulted in a percent difference of $+58.7 \%$ and a MAPE of $61.1 \%$ for the season. As discussed previously, we suspect that the MASC and PIP are not measuring snow microphysical distributions that are representative of those remotely sensed aloft by the MRR, ultimately biasing estimates high.

Given these potential biases with the in situ instrumentation, we returned to the temperature-dependent PSD $\lambda$ and MRR Doppler velocity scheme that produced reasonable values for the upslope seasonal statistics. This combination of inputs with the RA particle resulted in a percent difference of $+15.8 \%$ for seasonal snowfall accumulations with a MAPE of $29.6 \%$ relative to the DFAR. The use of the temperature-dependent PSD relationship forced the retrieval scheme to use larger particles than those observed by the MASC or PIP and thus decreased snowfall estimates in the retrieval. The use of MRR Doppler velocity allowed a fall speed metric that is less impacted by near-surface turbulence. Although biases in the selection of each PSD, particle, and fall speed could have conspired to produce good agreement between retrieval and snow gauges, it is nonetheless encouraging that we achieve such agreement for these turbulent mountain storms.

\section{Conclusions}

The High-Latitude Measurement of Snowfall (HiLaMS) campaign deployed a MRR, PIP, and MASC to the Haukeliseter Test Site run by the Norwegian Meteorological Institute during winter 2016/17. The overall goal of HiLaMS is to study snowfall microphysical properties and processes as a function of meteorological conditions, where results from Haukeliseter could be compared with those found for other project sites in Sweden and Alaska. In this work, we first characterized snowfall properties with the MASC and PIP as a function of distinct storm regimes at Haukeliseter. Using techniques outlined in $\mathrm{C} 17$, these observations were then used as input for an optimal-estimation-based snowfall retrieval algorithm based upon reflectivities from the ground-based, vertically pointing MRR. Snowfall estimates from this scheme then were compared with coincident DFAR observations.

For upslope storm events characterized by low winds and less intense precipitation, we obtained estimates of snowfall that agreed well with the DFAR. Use of in situ MASC and PIP observations with the RA model resulted in differences of $+9 \%$ and $-0.4 \%$, respectively, for cumulative accumulation totals over the season. Typical discrepancies were near $35 \%$ for individual snow events. 
TABLE 6. Differences in cumulative snowfall accumulation found between snowfall retrievals with the given assumptions and the Met Norway DFAR for all pulsed events during HiLaMS. When evaluating these comparisons, it is important to recall that studies have found typical mean undercatchment values of $10 \%$ for snow gauges similar to those at the Haukeliseter Test Site (Yang 2014).

\begin{tabular}{lllrr}
\hline \hline \multicolumn{1}{c}{ Particle model } & \multicolumn{1}{c}{ PSD $\lambda$} & \multicolumn{1}{c}{ Fall speed } & \% difference & MAPE \\
\hline Reflective (RA) & MASC & MASC & +48.9 & 52.7 \\
Reflective (RA) & PIP & Doppler velocity & +58.7 & 0.83 \\
Less reflective (LRA) & MASC & MASC & +138.6 & 0.1 \\
Reflective (RA) & Temperature-based & Doppler velocity & +15.8 & 138.6 \\
\hline
\end{tabular}

For pulsed events with windier conditions and more intense precipitation, the snowfall retrieval scheme performed poorly when using in situ observations of snowflake microphysics. The use of MASC PSD $\lambda$ and fall speed observations with the RA particle led to differences of $+49 \%$ in snowfall totals over the season with typical discrepancies of $53 \%$ for individual snow events. For these high wind events, the MASC predominately captured images of small blowing snow crystals that likely were not representative of the precipitation that the MRR was seeing aloft. Assumption of too narrow of a PSD would bias the snowfall retrieval high, as the dominance of small particles would require more snow water content to match MRR reflectivities than would broader PSDs with more large snowflakes.

We did not perform similar retrievals for the pulsed storms using PIP in situ observations. Near-surface turbulence resulted in very small or even "negative" fall speeds at the surface even when averaged over these storm events. As such, we employed microphysical metrics less impacted by surface turbulence in attempt to provide reasonable snow estimates for these pulsed events. For example, use of MRR Doppler velocities with the temperature-dependent PSD parameterization produced better results than the in situ observations with a difference of only $+16 \%$ relative to the DFAR for snowfall accumulations for the season.

Overall, these results suggest that the MRR-PIPMASC snowfall retrieval scheme has potential for accurately estimating snowfall rate but that the combination of preferred measurements for the scheme will depend upon specific meteorological conditions and instrument capabilities. However, these conclusions all depend upon the use of a snowflake particle model in the retrieval scheme that is well matched to scene environmental conditions. For Haukeliseter, the MASC nearly always observed rimed aggregates that are consistent with expected high water content conditions in this region. These MASC observations then were used as guide to select a compact, highly reflective aggregate particle model (RA) for the retrieval scheme. The use of the RA model produced good agreement with the DFAR as described above. The use of a different, less-reflective snow particle aggregate model (LRA) with MASC PSD $\lambda$ and fall speed observations led to differences of $+78 \%$ and $+139 \%$ for snowfall accumulations for the upslope and pulsed events, respectively, for the season.

The second part of the HiLaMS campaign took place in Kiruna, Sweden, from October 2017 to April 2018. Observations there focused on characterizing snowfall for a taiga forest location with a subarctic climate classification. Together with the observations from Haukeliseter presented here and Barrow, Alaska (C17), the findings will provide a better understanding of the variance in high-latitude snowfall properties and processes. For example, retrieved surface snowfall accumulations and vertical profiles of SWC provide a means to evaluate their representation in either numerical weather prediction or climate model simulations. These observational constraints also should provide insights into the relationship between the hydrologic and energy cycles that help drive climate change scenarios.

Acknowledgments. We thank Walt Petersen and Larry Bliven of NASA for use of the PIP for both the Haukeliseter and Kiruna campaigns. We thank Franziska Hellmuth and Rich Moore for information about the Haukeliseter Test Site. Schirle and Cooper were supported through National Science Foundation Grant 1531930. L'Ecuyer, Wood, and Pettersen were supported through National Science Foundation Grant 1531690.

\section{REFERENCES}

Bekryaev, R. V., I. V. Polyakov, and V. A. Alexeev, 2010: Role of polar amplification in long-term surface air temperature variations and modern arctic warming. J. Climate, 23, 3888-3906, https://doi.org/10.1175/2010JCLI3297.1.

Bindoff, N. L., and Coauthors, 2013: Detection and attribution of climate change: From global to regional. Climate Change 2013. The Physical Science Basis, T. F. Stocker et al., Eds., Cambridge University Press, 867-952.

Black, R. F., 1954: Precipitation at Barrow, Alaska, greater than recorded. Eos, Trans. Amer. Geophys. Union, 35, 203-207, https://doi.org/10.1029/TR035i002p00203.

Brown, R., 2000: Northern Hemisphere snow cover variability and change, 1915-97. J. Climate, 13, 2339-2355, https://doi.org/ 10.1175/1520-0442(2000)013<2339:NHSCVA > 2.0.CO;2. 
Chapman, W. L., and J. E. Walsh, 1993: Recent variations of sea ice and air temperature in high latitudes. Bull. Amer. Meteor. Soc., 74, 33-47, https://doi.org/10.1175/1520-0477(1993) 074<0033:RVOSIA > 2.0.CO;2.

Cohen, J. L., and D. Rind, 1991: The effect of snow cover on the climate. J. Climate, 4, 689-706, https://doi.org/10.1175/ 1520-0442(1991)004<0689:TEOSCO > 2.0.CO;2.

Cooper, S. J., N. B. Wood, and T. S. L'Ecuyer, 2017: A variational technique to estimate snowfall rate from coincident radar, snowflake, and fallspeed observations. Atmos. Meas. Tech., 10, 2557-2571, https://doi.org/10.5194/amt-10-2557-2017.

Crook, J. A., P. M. Forster, and N. Stuber, 2011: Spatial patterns of modeled climate feedback and contributions to temperature response and polar amplification. J. Climate, 24, 3575-3592, https://doi.org/10.1175/2011JCLI3863.1.

Draine, B. T., and P. J. Flatau, 1994: Discrete-dipole approximation for scattering calculations. J. Opt. Soc. Amer., 11A, 1491-1499, https://doi.org/10.1364/JOSAA.11.001491.

Folland, C., 1988: Numerical models of the raingauge exposure problem, field experiments and an improved collector design Quart. J. Roy. Meteor. Soc., 114, 1485-1516, https://doi.org/ 10.1002/qj.49711448407.

Gardner, A. S., and Coauthors, 2013: A reconciled estimate of glacier contributions to sea level rise: 2003 to 2009. Science, 340, 852-857, https://doi.org/10.1126/science.1234532.

Garrett, T. J., and S. E. Yuter, 2014: Observed influence of riming, temperature, and turbulence on the fallspeed of solid precipitation. Geophys. Res. Lett., 41, 6515-6522, https://doi.org/ 10.1002/2014GL061016.

— C. Fallgatter, K. Shurko, and D. Howlett, 2012: Fallspeed measurement and high-resolution multi-angle photography of hydrometeors in freefall. Atmos. Meas. Tech. Discuss., 5, 4827-4850, https://doi.org/10.5194/amtd-5-4827-2012.

— S. E. Yuter, C. Fallgatter, K. Shkurko, S. R. Rhodes, and J. L. Endries, 2015: Orientations and aspect ratios of falling snow. Geophys. Res. Lett., 42, 4617-4622, https://doi.org/10.1002/ 2015 GL064040.

Goodison, B. E., P. Y. T. Louie, and D. Yang, 1998: WMO solid precipitation measurement intercomparison. WMO Instruments and Observing Methods Rep. 67, WMO/TD-872, 212 pp.

Hammonds, K. D., G. G. Mace, and S. Y. Matrosov, 2014: Characterizing the radar backscatter-cross-section sensitivities of ice-phase hydrometeor size distributions via a simple scaling of the Clausius-Mossotti factor. J. Appl. Meteor. Climatol., 53, 2761-2774, https://doi.org/10.1175/JAMC-D-13-0280.1.

Holland, M. M., and C. M. Bitz, 2003: Polar amplification of climate change in coupled models. Climate Dyn., 21, 221-232, https:// doi.org/10.1007/s00382-003-0332-6.

$\longrightarrow,-$, and L.-B. Tremblay, 2006: Future abrupt reductions in the summer arctic sea ice. Geophys. Res. Lett., 33, L23503, https://doi.org/10.1029/2006GL028024.

Hudak, D., H. Barker, P. Rodriguez, and D. Donovan, 2006: The Canadian CloudSat validation project. Proc. Fourth European Conf. on Radar in Hydrology and Meteorology, Barcelona, Spain, CRAHI, 609-612, http://www.crahi.upc.edu/ERAD2006/ proceedingsMask/00165.pdf.

Jacob, T., J. Wahr, W. T. Pfeffer, and S. Swenson, 2012: Recent contributions of glaciers and ice caps to sea level rise. Nature, 482, 514-518, https://doi.org/10.1038/nature10847.

Kleinkort, C., G.-J. Huang, V. N. Bringi, and B. M. Notaroš, 2017: Visual hull method for realistic 3D particle shape reconstruction based on high-resolution photographs of snowflakes in freefall from multiple views. J. Atmos. Oceanic Technol., 34, 679-702, https://doi.org/10.1175/JTECH-D-16-0099.1.
Klugmann, D., K. Heinsohn, and H. Kirtzel, 1996: A low cost $24 \mathrm{GHz}$ FM-CW Doppler radar rain profiler. Contrib. Atmos. Phys., 69, 247-253.

Kochendorfer, J., and Coauthors, 2018: Testing and development of transfer functions for weighing precipitation gauges in WMO-SPICE. Hydrol. Earth Syst. Sci., 22, 1437-1452, https:// doi.org/10.5194/hess-22-1437-2018.

Kulie, M., and R. Bennartz, 2009: Utilizing spaceborne radars to retrieve dry snowfall. J. Appl. Meteor., 48, 2564-2580, https:// doi.org/10.1175/2009JAMC2193.1.

Larson, L. W., and E. L. Peck, 1974: Accuracy of precipitation measurements for hydrologic modeling. Water Resour. Res., 10, 857-863, https://doi.org/10.1029/WR010i004p00857.

Lenaerts, J., E. Meijgaard, M. R. Broeke, S. R. M. Ligtenberg, M. Horwath, and E. Isaksson, 2013: Recent snowfall anomalies in Dronning Maud Land, East Antarctica, in a historical and future climate perspective. Geophys. Res. Lett., 40, 2684-2688, https://doi.org/10.1002/grl.50559.

Liu, G., 2008: Deriving snow cloud characteristics from CloudSat observations. J. Geophys. Res., 113, D00A09, https://doi.org/ 10.1029/2007JD009766.

Maahn, M., and P. Kollias, 2012: Improved Micro Rain Radar snow measurements using Doppler spectra post-processing. Atmos. Meas. Tech., 5, 2661-2673, https://doi.org/10.5194/ amt-5-2661-2012.

Manabe, S., and R. J. Stouffer, 1980: Sensitivity of a global climate model to an increase of $\mathrm{CO}_{2}$ concentration in the atmosphere. J. Geophys. Res., 85, 5529-5554, https://doi.org/10.1029/ JC085iC10p05529.

Matrosov, S. Y., M. D. Shupe, and I. V. Djalalova, 2008: Snowfall retrievals using millimeter wavelength cloud radars. J. Appl. Meteor. Climatol., 47, 769-777, https://doi.org/10.1175/ 2007JAMC1768.1.

Mitchell, D. L., 1996: Use of mass- and area-dimensional power laws for determining precipitation particle terminal velocities. J. Atmos. Sci., 53, 1710-1723, https://doi.org/10.1175/ 1520-0469(1996)053<1710:UOMAAD > 2.0.CO;2.

Newman, A. J., P. A. Kucera, and L. F. Bliven, 2009: Presenting the snowflake video imager (SVI). J. Atmos. Oceanic Technol., 26, 167-179, https://doi.org/10.1175/2008JTECHA1148.1.

Nicholls, N., G. V. Gruza, J. Jouzel, T. R. Karl, L. A. Ogallo, and D. E. Parker, 1996: Observed climate variability and change. Climate Change 1995: The Science of Climate Change, J. T. Houghton et al., Eds., Cambridge University Press, 137-192.

Palerme, C., J. E. Kay, C. Genthon, T. L'Ecuyer, N. B. Wood, and C. Claud, 2014: How much snow falls on the Antarctic ice sheet? Cryosphere, 8, 1577-1587, https://doi.org/10.5194/tc-8-1577-2014.

_ C. Genthon, C. Claud, J. E. Kay, N. B. Wood, and T. L'Ecuyer, 2017: Evaluation of current and projected Antarctic precipitation in CMIP5 models. Climate Dyn., 48, 225-239, https:// doi.org/10.1007/s00382-016-3071-1.

Passarelli, R. E., Jr., 1978: Theoretical and observational study of snow-size spectra and snowflake aggregation efficiencies. J. Atmos. Sci., 35, 882-889, https://doi.org/10.1175/1520-0469(1978) 035<0882:TAOSOS $>2.0 . \mathrm{CO} ; 2$.

Pettersen, C., R. Bennartz, A. J. Merrelli, M. D. Shupe, D. D. Turner, and V. P. Walden, 2018: Precipitation regimes over central Greenland inferred from 5 years of ICECAPS observations. Atmos. Chem. Phys., 18, 4715-4735, https://doi.org/ 10.5194/acp-18-4715-2018.

Rasmussen, R., and Coauthors, 2012: How well are we measuring snow? The NOAA/FAA/NCAR winter precipitation test bed. Bull. Amer. Meteor. Soc., 93, 811-829, https://doi.org/10.1175/ BAMS-D-11-00052.1. 
Rodgers, C., 2000: Inverse Methods for Atmospheric Sounding. World Scientific Publishing, 240 pp.

Screen, J. A., and I. Simmonds, 2010: The central role of diminishing sea ice in recent arctic temperature amplification. Nature, 464, 1334-1337, https://doi.org/10.1038/nature09051.

Serreze, M. C., and J. A. Francis, 2006: The Arctic on the fast track of change. Weather, 61, 65-69, https://doi.org/10.1256/wea.197.05.

Shepherd, A., and D. Wingham, 2007: Recent sea-level contributions of the Antarctic and Greenland ice sheets. Science, 315, 1529-1532, https://doi.org/10.1126/science.1136776.

Steensen, B. M., H. Olafsson, and M. O. Jonassen, 2011: An extreme precipitation event in central Norway. Tellus, 63, 675-686, https://doi.org/10.1111/j.1600-0870.2011.00522.x.

Stephens, G. L., D. Winker, J. Pelon, C. Trepte, D. Vane, C. Yuhas, T. L'Ecuyer, and M. Lebsock, 2018: CloudSat and CALIPSO within the A-Train: Ten years of actively observing the Earth system. Bull. Amer. Meteor. Soc., 99, 569-581, https://doi.org/ 10.1175/BAMS-D-16-0324.1.

Stohl, A., C. Forster, and H. Sodemann, 2008: Remote sources of water vapor forming precipitation on the Norwegian west coast at $60^{\circ} \mathrm{N}-\mathrm{A}$ tale of hurricanes and an atmospheric river. J. Geophys. Res., 113, D05102, https://doi.org/10.1029/2007JD009006.

Thériault, J. M., R. Rasmussen, E. Petro, J. Y. Trepanier, M. Colli, and L. D. Lanza, 2015: Impact of wind direction, wind speed, and particle characteristics on the collection efficiency of the double fence intercomparison reference. J. Appl. Meteor. Climatol., 54, 1918-1930, https://doi.org/10.1175/JAMC-D-15-0034.1.

Tiira, J., D. N. Moisseev, A. von Lerber, D. Ori, A. Tokay, L. F. Bliven, and W. Petersen, 2016: Ensemble mean density and its connection to other microphysical properties of falling snow as observed in southern Finland. Atmos. Meas. Tech., 9, 4825-4841, https://doi.org/10.5194/amt-9-4825-2016.

Van Tricht, K., and Coauthors, 2016: Clouds enhance Greenland ice sheet meltwater runoff. Nat. Commun., 7, 10266, https:// doi.org/10.1038/ncomms10266.

Vavrus, S., 2007: The role of terrestrial snow cover in the climate system. Climate Dyn., 29, 73-88, https://doi.org/10.1007/ s00382-007-0226-0.

Waliser, D., and B. Guan, 2017: Extreme winds and precipitation during landfall of atmospheric rivers. Nat. Geosci., 10, 179-183, https://doi.org/10.1038/ngeo2894.
Wernli, H., and C. Schwierz, 2006: Surface cyclones in the ERA-40 dataset (1958-2001). Part I: Novel identification method and global climatology. J. Atmos. Sci., 63, 2486-2507, https:// doi.org/10.1175/JAS3766.1.

Wolff, M. A., K. Isaksen, A. Petersen-Øverlier, K. Ødemark, T. Reitan, and R. Brækkan, 2015: Derivation of a new continuous adjustment function for correcting wind-induced loss of solid precipitation: Results of a Norwegian field study. Hydrol. Earth Syst. Sci., 19, 951-967, https://doi.org/10.5194/ hess-19-951-2015.

Wood, N. B., 2011: Estimation of snow microphysical properties with application to millimeter wavelength radar retrievals for snowfall rate. Ph.D. dissertation, Colorado State University, 248 pp., http://hdl.handle.net/10217/48170.

—_, and T. S. L'Ecuyer, 2018: Level 2C snow profile product process description and interface control document, product version P1_R05. NASA Jet Propulsion Laboratory CloudSat project document revision 0, 26 pp., http:// www.cloudsat.cira.colostate.edu/sites/default/files/products/files/ 2C-SNOW-PROFILE_PDICD.P1_R05.rev0_.pdf.

,-- A. J. Heymsfield, G. L. Stephens, D. R. Hudak, and P. Rodriguez, 2014: Estimating snow microphysical properties using collocated multisensor observations. J. Geophys. Res. Atmos., 119, 8941-8961, https://doi.org/10.1002/2013JD021303.

,,--- , and -2015 : Microphysical constraints on millimeter-wavelength scattering properties of snow particles. J. Appl. Meteor. Climatol., 54, 909-931, https://doi.org/ 10.1175/JAMC-D-14-0137.1.

Yang, D., 2014: Double Fence Intercomparison Reference (DFIR) vs. Bush Gauge for "true" snowfall measurement. J. Hydrol., 509, 94-100, https://doi.org/10.1016/j.jhydrol.2013.08.052.

B. E. Goodison, J. R. Metcalfe, V. S. Golubev, R. Bates, T. Pangburn, and C. L. Hanson, 1998: Accuracy of NWS 8" standard nonrecording precipitation gauge: Results and application of WMO intercomparison. J. Atmos. Oceanic. Technol., 15, 54-68, https://doi.org/10.1175/1520-0426(1998) $015<0054$ :AONSNP $>2.0$. CO; 2 .

- D. Kane, Z. Zhang, D. Legates, and B. Goodison, 2005: Bias corrections of long-term (1973-2004) daily precipitation data over the northern regions. Geophys. Res. Lett., 32, L19501, https://doi.org/10.1029/2005GL024057. 